$\sqrt{3}$

J. bio-sci. 20: 33-39, 2012

ISSN 1023-8654

http://www.banglajol.info/index.php/JBS/index

\title{
SWITCHING THE ENZYMATIC ACTIVITY OF RIBONUCLEASE A BASED ON ENZYME/POLYMER COMPLEX FORMATION
}

\author{
Sumon Ganguli* \\ Faculty of Science, Department of Applied and Environmental Chemistry, \\ University of Chittagong, Chittagong-4331, Bangladesh.
}

\begin{abstract}
Context: Enzymes are ideal for various applications in both medicine and biotechnology. Switching on/off the enzymatic activity of enzymes by polymeric modification would expand the applications of enzymes in a wide range of research fields.

Objectives: On/off switching the enzymatic activity of RNase $A$ and the confirmation of the enzyme/polymer complex formation which leads to improve the heat resistance of RNase A.

Materials and Methods: a-Methoxy- $\omega$-methacryloyl poly (ethylene glycol) (PEG-MA) macromonomer and PEAMA-g-PEG were synthesized. Bovine RNase A, cytidine 2',3'-cyclic monophosphate sodium salt (cCMP), and 3-(N-morpholino)propanesulfonic acid (MOPS) were obtained from Sigma Chemical Co. (St. Louis, USA). PAAc $\left(M_{\mathrm{n}}=5,000 \mathrm{~g} / \mathrm{mol}\right)$ were purchased from Wako (Osaka, Japan). Sodium dihydrogen phosphate dihydrate $\left(\mathrm{NaH}_{2} \mathrm{PO}_{4} .2 \mathrm{H}_{2} \mathrm{O}\right)$ was obtained from Nacalai Tesque Inc. (Kyoto, Japan). The enzymatic activity of RNase A was estimated as follows. The RNase A concentration was determined by measuring the absorbance at $280 \mathrm{~nm}$ with an appropritate blank, using an extinction coefficient of 7.10 $\mathrm{mL} \mathrm{mg}{ }^{-1} \mathrm{~cm}^{-1}$. A total of $1.5 \mathrm{~mL}$ of $0.1 \mathrm{mg} / \mathrm{mL}$ cCMP solution prepared in $0.1 \mathrm{M}$ MOPS (pH 7.0) was mixed with $10 \mu \mathrm{L}$ of the RNase A solution in $50 \mathrm{mM}$ sodium phosphate buffer ( $\mathrm{pH}$ 7.0). The increase in light scattering intensity of the solution was monitored by measuring the absorbance at $284 \mathrm{~nm}$ for $60 \mathrm{~s}$ in a UV-vis spectrophotometer at room temperature. After heat treatment, the enzymatic activities were measured. Far-UV and near-UV CD spectra were monitored using a spectropolarimeter (model J-720W; Jasco, Tokyo, Japan).

Results: We have found that poly (acrylic acid) (PAAc) suppressed the enzymatic activity of RNase A completely and the recovery of enzymatic activity were observed (94\%) by the external addition of PEAMA-g-PEG to the RNase A/PAAC complex. Our present findings suggest that the complexation between PEAMA-g-PEG and RNase A has occurred which improve the heat resistance $(64 \%)$ of RNase A. Heat treatment has been carried out at $98^{\circ} \mathrm{C}$ for 10 minutes where the native RNase A lost all of its enzymatic activity. $C D$ spectral analysis also indicates that the conformation of the enzyme was not altered due to the complexation.

Conclusion: Poly (N,N-diethylaminoethyl methacrylate)-graft-poly (ethylene glycol) (PEAMA-g-PEG) restored the enzymatic activity of RNase $A$ completely which was inactivated upon the addition of poly(acrylic acid) (PAAc) to RNase A. Complexation of RNase A with PEAMA-g-PEG induced the improvement of heat resistance of RNase $A$. Circular dichroism (CD) spectral analysis clearly indicated that the complexation of enzyme with polymer has almost no influence on the conformation of enzyme.
\end{abstract}

Keywords: Switching, Enzymatic activity, PEAMA-g-PEG, RNase A, Heat resistance, Complexation.

\section{Introduction}

Enzymes have attracted great attention in biomaterials education. Switching on/off the enzymatic activity of enzymes would expand the applications of enzymes in a wide range of research fields including biosensors, bioreactors, and highly sophisticated drug/enzyme delivery systems. To regulate the enzymatic activity, several process have been developed such as covalent modifications of a ligand (Corey and Schultz 1989),

* Corresponding address E-mail: sumonganguli@yahoo.com 
stimuli sensitive polymers (Shimoboji et al. 2002), switching by metal (Corey and Schultz 1989), as well as by nanoparticles (Sandaraj et al. 2005). However, denaturation is the major obstacles to the application of enzymes. Enzymes are inactivated under extreme conditions due to the denaturation, which limit their applications in various fields. Given the versatile applications of enzymes, proper controlling of their reactivity and the increase in their stability under extreme conditions such as high temperatures, high or low pHs, and organic solvents are of important subjects, introducing a new field of study on enzyme modifications. Here it is noteworthy to note that the cost effective and easy procedure is long awaited. Based on several previous studies attractive and repulsive electrostatic interactions have been considered important for the switching (Verma et al. 2004, Tanaka et al. 2006, Harada et al. 2007, Wenck et al. 2007); and stabilization (Schumann et al. 1993, Ganguli et al. 2009) of enzymes. In addition, charged polymeric compounds are particularly attractive agents for complexation with enzymes. Recently, we succeeded in regulating the enzymatic activity and concomitantly improving the heat resistance of lysozyme (Ganguli et al. 2010) through the external addition of a polycationic polyamine-poly (ethylene glycol) (PEG) graft copolymer, poly ( $N, N$ diethylaminoethyl methacrylate)-graft-PEG (PEAMA-g-PEG). Since switching the enzymatic activity is of great importance in various fields such as enzyme delivery and stabilization, in the present study, the simple and inexpensive procedure have been applied successfully in the case of another enzyme ribonuclease $A$ (RNase A) with a anionic polymer poly (acrylic acid) (PAAc) and a cationic smart copolymer, poly ( $N, N-$ diethylaminoethyl methacrylate)-graft-poly(ethylene glycol) (PEAMA-g-PEG).

\section{Materials and Methods}

\section{Materials}

a-Methoxy- $\omega$-methacryloyl poly(ethylene glycol) (PEG-MA) macromonomer and PEAMA-g-PEG were synthesized as described in our previous article (Ganguli et al. 2009). PEAMA-g-PEG was used after HPLC purification. Bovine RNase A, cytidine 2',3'-cyclic monophosphate sodium salt (CCMP), and 3-( $N$ morpholino)propanesulfonic acid (MOPS) were obtained from Sigma Chemical Co. (St. Louis, USA). PAAc $\left(M_{\mathrm{n}}=5,000 \mathrm{~g} / \mathrm{mol}\right)$ were purchased from Wako (Osaka, Japan). Sodium dihydrogen phosphate dihydrate $\left(\mathrm{NaH}_{2} \mathrm{PO}_{4} .2 \mathrm{H}_{2} \mathrm{O}\right)$ was obtained from Nacalai Tesque Inc. (Kyoto, Japan). All chemicals used were of highquality analytical grade. The water used in this study was purified using the Milli-Q system (Nihon Millipore Co., Tokyo, Japan).

\section{Enzymatic activity measurements}

The enzymatic activity of RNase A was estimated as follows. The RNase A concentration was determined by measuring the absorbance at $280 \mathrm{~nm}$ with an appropritate blank, using an extinction coefficient of $7.10 \mathrm{~mL} \mathrm{mg}^{-1} \mathrm{~cm}^{-1}$. A total of $1.5 \mathrm{~mL}$ of $0.1 \mathrm{mg} / \mathrm{mL} \mathrm{cCMP}$ solution prepared in $0.1 \mathrm{M}$ MOPS (pH 7.0) was mixed with $10 \mu \mathrm{L}$ of the RNase A solution in $50 \mathrm{mM}$ sodium phosphate buffer (pH 7.0). The increase in light scattering intensity of the solution was monitored by measuring the absorbance at $284 \mathrm{~nm}$ for $60 \mathrm{~s}$ in a UV-vis spectrophotometer (model V-550; Japan Spectroscopic Co., Tokyo, Japan) at room temperature. The absorbance plots from $10 \mathrm{~s}$ to $20 \mathrm{~s}$ were fitted to a linear equation, and the enzymatic activities were determined from the slope of the fitted line (Ganguli et al. 2009). Heatinactivation of a ternary mixture of RNase A/PAAc/PEAMA-g-PEG was performed as follows. A solution was prepared that contained $2.5 \mathrm{mg} / \mathrm{mL}$ RNase A in $50 \mathrm{mM}$ sodium phosphate buffer (pH 7.0), $10 \mathrm{mg} / \mathrm{mL}$ of PAAc and 0-20 mg/mL PEAMA-g-PEG. The enzyme solutions $(100 \mu \mathrm{L})$ were heated at $98^{\circ} \mathrm{C}$ for $10 \mathrm{~min}$ using the PC-880 temperature control system (Astec, Fukuoka, Japan). After heat treatment, the enzymatic activities were measured as described above. All the measurements were performed three times and the standard errors were plotted.

\section{CD spectra measurements}

Far-UV CD spectra were monitored using a spectropolarimeter (Model J-720W; Jasco, Tokyo, Japan). A cuvette with $0.1-\mathrm{cm}$ path length was used, and the photomultiplier voltage did not exceed $600 \mathrm{~V}$ during the measurements. The results are expressed in terms of residue molar ellipticity. 


\section{Results and Discussion}

$\mathrm{n}$ our previous study, we found that the enzymatic activity of lysozyme was suppressed by PEAMA-g-PEG owing to capping of the active site of lysozyme, which involved an electrostatic interaction between the negatively charged active site of lysozyme and the positively charged amine moiety of PEAMA-g-PEG at neutral $\mathrm{pH}$ (Ganguli et al. 2009). In addition, we evaluated the effect of using only PEAMA-g-PEG on the enzymatic activity and heat resistance of RNase A, which is composed of 124 amino acid residues, has a positive net charge at neutral pH (Ganguli et al. 2010). According to X-ray crystallography results, the active site of RNase A has four positively charged residues, which play an important role in the enzymatic function of this enzyme (Borkakoti 1983). Given the net positive charge at neutral pH of RNase A as well as the negatively charged amine moiety at the active site of RNase $A$, it was used as the model enzyme in the present study. To show the switching of enzymatic activity of RNase A using polymer, the present study is unique. It should be noted that we have used PAAC and PEAMA-g-PEG to inactivate and reactivate the enzyme in the present study. The present study shows the versality of using PEAMA-g-PEG to study the switching of enzymatic activity of RNAse A for the first time and also gives another proof that the complexation of RNase A with PEAMA-g-PEG which leads to improved thermal stability.

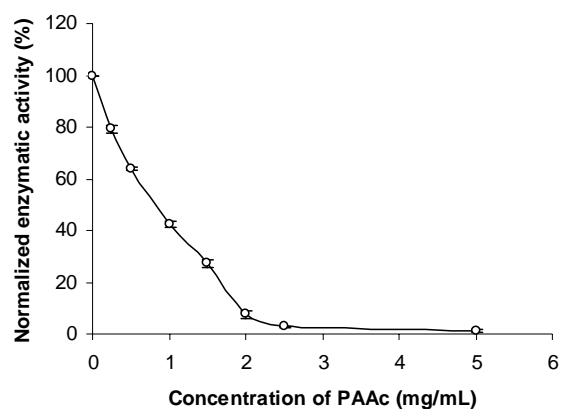

Fig. 1. Changes in the normalized enzymatic activity of RNase $A$ in the presence of (O) PAAc, as a function of the polymer concentration. The samples contained $2.5 \mathrm{mg} / \mathrm{mL}$ RNase A and 0$5 \mathrm{mg} / \mathrm{mL}$ PAAc. The enzymatic activities were measured at room temperature and $\mathrm{pH} 7.0$.

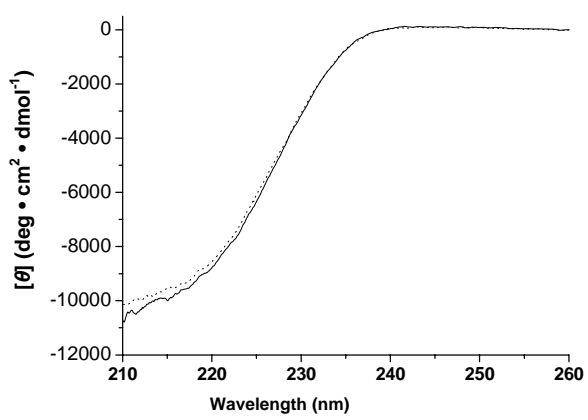

Fig. 2. (a) Far-UV CD spectra of RNase $A$ and the RNase A/PAAC complex. The samples contained $0.5 \mathrm{mg} / \mathrm{mL}$ RNase $A$ and 5 $\mathrm{mg} / \mathrm{mL}$ PAAc. Measurements were carried out at $25^{\circ} \mathrm{C}$ and $\mathrm{pH}$ 7.0.

Figure 1 shows the changes of enzymatic activity of RNase A using PAAc. The polyanion PAAc showed a significant effect on the enzymatic activity of RNase A when PAAc was mixed with the RNase A. The enzymatic activity completely disappeared in the presence of PAAc at concentrations above $2.5 \mathrm{mg} / \mathrm{mL}$, suggesting the strong interaction between RNase $A$ and PAAc. In order to obtain information on the conformational change in the complexation step of RNase A with PAAC, a CD spectrum (Far-UV CD spectra) of the RNase $A$ and its polymer complex was obtained. The far-UV CD spectrum of a protein generally reflects its secondary structure (Sreerama and Woddy 2000). Any conformational change leads to the distortion of the $C D$ spectrum. As shown in Figure 2, there was no difference in the CD spectra between RNase $A$ and the RNase A/PAAc complex, indicating no substantial changes in the secondary structure of RNase $A$ in the complexation step with PAAc. These results are also in line with the previously reported data (Kurinomaru et al. 2011). It should be noted that RNase A is composed of 124 residues and has a positive net charge of +4 at pH 7.0 (pI= 11) (Ganguli et al. 2010). Since it is well known that negatively charged polymers interact with positively charged enzymes effectively (Harada and Kataoka 2003), it is undoubtedly suggested that this negatively charged PAAc formed RNase A/PAAc complex substantially by electrostatic 
interaction. It can not be ruled out that the hydrophobic interaction between the hydrophobic amino acid of RNase $A$ and the hydrophobic PEAMA segment of the PEAMA-g-PEG. PAAc has a negative charge at neutral $\mathrm{pH}$, so that it is suggested that the electrostatic interaction between the negatively charged PAAc to the surface of the RNase $A$ leads to the inhibition of the substrate attack into the active site of RNase A, resulting in a decrease in RNase $A$ activity. The active site of RNase $A$ is located between $\alpha$-domain and $\beta$ domain where the enzymatic activity is originated. These results indicate that PAAc interacted with RNase $A$ effectively, resulting in the complete inactivation of its enzymatic activity by electrostatic interaction coupled with hydrophobic interaction, but that the secondary structure of RNase A was maintained in the RNase A/PAAc complex.

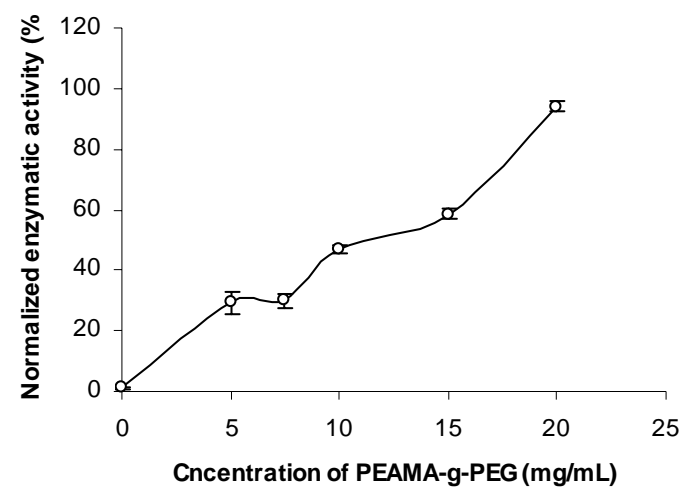

Fig. 3. Recovery of the enzymatic activity of the RNase A/PAAc complex upon the addition of PEAMA-g-PEG. All samples contained $2.5 \mathrm{mg} / \mathrm{mL}$ RNase A with $10 \mathrm{mg} / \mathrm{mL}$ PAAc, and measurements were carried out at room temperature and $\mathrm{pH} 7.0$.

In order to evaluate the electrostatic interaction between RNase $A$ and PAAc, an exchange reaction with the cationic polymer PEAMA-g-PEG was carried out and the variations in the enzymatic activity of the RNase A/PAAc complex were monitored. It is widely known that oppositely charged macromolecules strongly interact through multiple electrostatic interactions to form a polyion-complex (PIC) (Bronich et al.1997; Katayose and Kataoka 1997). Figure 3 shows the recovery of the enzymatic activity of RNase A in the RNase A/PAAc complex as a result of the addition of PEAMA-g-PEG. It was observed that the enzymatic activity of the complex completely recovered to the level of the native RNase A (94\%) upon the addition of $20 \mathrm{mg} / \mathrm{mL}$ PEAMA-g-PEG. These results indicate that the RNase A was released from the RNase A/PAAc complex due to the PIC formation of PAAc with PEAMA-g-PEG. This result can also be explained by the fact that the active site of the RNase A was remained open due to the formation of the PIC and the substrate can access the active site easily leading to the recovery of the RNase A activity. In addition, it is also anticipated that hydrophobic interaction still exists on the polymer-enzyme interface rather than the active site as well as electrostatic interaction to some extent. It was revealed that PAAc inactivate the RNase A activity completely and PEAMA-g-PEG significantly restored the enzymatic activity of RNase A. Taken together, switching of RNase $A$ activity using PAAC and PEAMA-g-PEG system was demonstrated which shows the versality of using our synthesized graft copolymer, PEAMA-g-PEG to regulate the enzymatic activity not only for lysozyme (Ganguli et al. 2009) but also for RNase A. 
PEAMA-g-PEG is a novel modifying agent that prevents the inactivation and aggregation of certain types of heat-labile enzymes as proved in our previous published papers (Ganguli et al. 2009; Ganguli et al. 2010). It is hypothesized that the addition of only PEAMA-g-PEG improves the heat resistance of RNase $A$, due to the complex formation between RNase A and PEAMA-g-PEG by the combination of electrostatic and hydrophobic interaction (Ganguli et al. 2010). It is known that the native RNase A $(2.5 \mathrm{mg} / \mathrm{mL})$ lost of all its enzymatic activity after $10 \mathrm{~min}$ of heating at $98^{\circ} \mathrm{C}$ (Ganguli 2010). In order to check the complexation of RNase A/PEAMA-g-PEG has occurred to improve the heat resistance of RNase $A$ even though the PIC formation between PAAC/PEAMA-g-PEG, we apply heat treatment $\left(98^{\circ} \mathrm{C}\right.$ for $\left.10 \mathrm{~min}\right)$ on the ternary mixture of RNase A/PAAC/PEAMA-g-PEG, and the enzymatic activity of RNase A was monitored against the concentration of PEAMA-g-PEG as represented in Figure 4. . It should be noted that after the addition of 20 $\mathrm{mg} / \mathrm{mL}$ of PEAMA-g-PEG, the enzymatic activity of RNase A was maintained up to $94 \%$ (Figure 3).The enzymatic activity of RNase $A$ in the ternary mixture of RNase A/PAAC/PEAMA-g-PEG after the heat treatment was found to $64 \%$. The decreasing trend of enzymatic activity (94\% to $64 \%)$ is due to the PIC formation between PAAc and PEAMA- $g$-PEG which leads to the release of RNase A from the complex, so that the released RNase A was inactivated because of the heat treatment. In addition, it must be said that RNase $A$ is still alive in aqueous solution even after the heat treatment. Therefore, it can be anticipated some RNase A molecules formed a complex with PEAMA-g-PEG and this graft copolymer induced the heat resistance of RNase $A$. In our previous study, after treatment at $98^{\circ} \mathrm{C}$ for $10 \mathrm{~min}$, the enzymatic activity of RNase A complexed with only PEAMA-g-PEG $(20 \mathrm{mg} / \mathrm{mL})$ was recovered to $75 \%$ of the level of the native RNase A (Ganguli et al. 2010). We assumed that the prevention of irreversible heat-inactivation of the enzyme can be accomplished by the interaction between PEAMA and amino acid residues on the enzyme surface, whereby the electrostatic and hydrophobic interactions take place on the polymer-enzyme interface. In the present study, the preserved enzymatic activity of RNase A (64\%) in presence of $20 \mathrm{mg} / \mathrm{mL}$ PEAMA-gPEG is presumably suggest that the complexation between RNase $A$ and PEAMA-g-PEG has occurred. The chemical structures of PEAMA-g-PEG were placed as Figure 5.

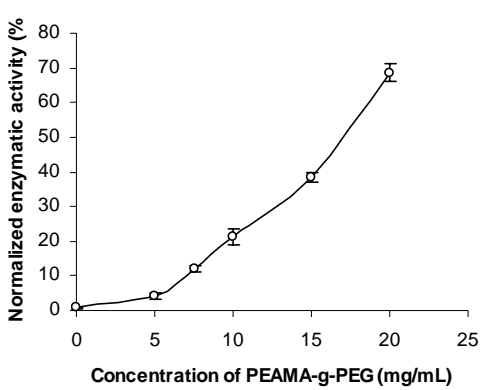

Fig.4. Changes in the enzymatic activity of RNase $A$ in the ternary mixture of RNase A/PAAC/PEAMA-g-PEG after the heat treatment against the concentration of PEAMA-g-PEG. The concentration of RNase A, PAAc and PEAMA-g-PEG was $2.5 \mathrm{mg} / \mathrm{mL}, 10 \mathrm{mg} / \mathrm{mL}$, and $0-20 \mathrm{mg} / \mathrm{mL}$, respectively. Heat treatment was carried out at $98{ }^{\circ} \mathrm{C}$ for $10 \mathrm{~min}$, and then measurements were carried out at room temperature and $\mathrm{pH} 7.0$.

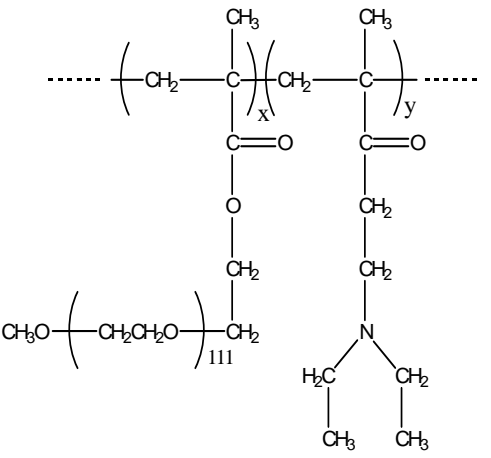

Fig. 5. The chemical structures of PEAMA-g-PEG. 


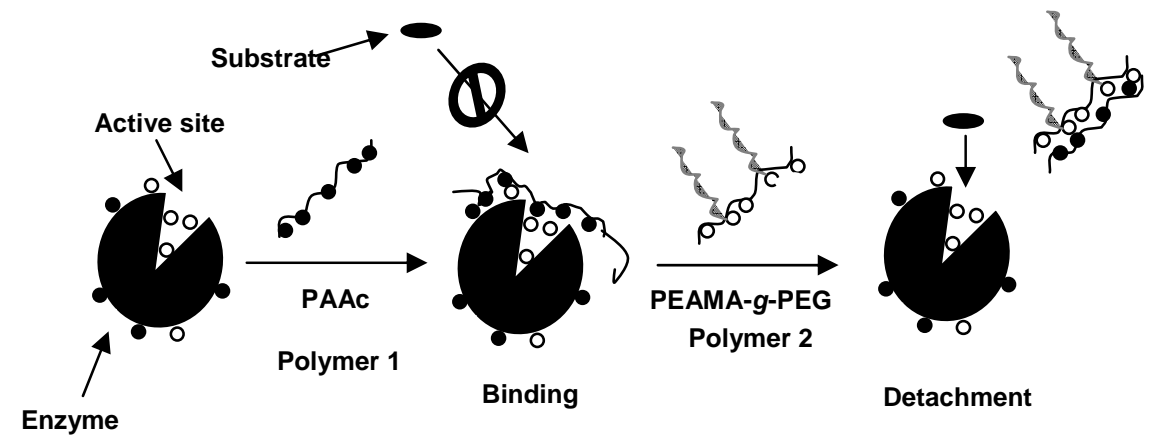

Scheme 1. Binding and detachment of enzyme/polymer complex.

Taken together, it can be illustrated that (Scheme 1) RNase A was inactivated (binding) by PAAc with the formation water-dispersed complexes and subsequently the enzymatic activity was successfully recovered (detachment) upon the addition of PEAMA-g-PEG. Regulation/Switching of RNase A activity as well as improving the heat resistance of RNase A using PAAc and PEAMA-g-PEG system was demonstrated which shows the versality of using our synthesized graft copolymer, PEAMA-g-PEG, for the improved switching system and suggested the formation of RNase A/PEAMA-g-PEG complex.

\section{Conclusion}

We developed smart copolymer, PEAMA-g-PEG, to establish water-dispersed enzyme/polymer complex. PEAMA-g-PEG successfully restored the enzymatic activity of RNase A which was completely inactivated upon the addition of PAAc. The complexation between RNase A with polymer has almost no influence on the secondary structure of enzyme. Improved heat resistance of RNase A is presumably suggesting the formation of RNase A/PEAMA-g-PEG complex. PEAMA-g-PEG was found to novel modifying agent for enzymes. We also would like to conclude that PEGylated charged polymers would be very useful to switch on/off the enzymatic activity. Complexation and decomplexation between polymer and enzyme with the maintained structure of enzyme offers new prospects for enzyme stabilization and delivery. This kind of strategy might be extended to regulate the enzymatic activity of other enzymes or the binding affinity of proteins to polymers, DNA or other proteins would expand the potential of enzyme in biomedical and biotechnological fields.

\section{Acknowledgements}

The authors gratefully acknowledge the Department of Applied and Environmental Chemistry, University of Chittagong, Chittagong-4331, Bangladesh. The author also would like to express sincere gratitude to Dr. Parimal Talukder, Manager, Research and Development, Square Pharmaceuticals Ltd. Bangladesh for the help to measure the enzymatic activity and Institute of Applied Physics, UT, Japan for CD measurements.

\section{References}

Corey DR, Schultz PG. 1989. Introduction of a Metal-Dependent Regulatory Switch into an Enzyme. J Bio Chem 264, 3666-3669.

Shimoboji T, Larenas E, Fowler T, Kulkarni S, Hoffman AS, Stayton PS. 2002. Photo responsive Polymer-Enzyme Switches. Pro Nat Acad Sci USA 99, 16592-16596. http://dx.doi.org/10.1073/pnas.262427799 
Sandaraj BS, Vutukuri DR, Simrad JM, Klaikherd A, Hong R, Rotello VM, Thayumanavan S. 2005. Non-covalent modification of Chymotrypsin surface using an amphiphilic polymer scaffold: implications in modulating protein function. J Am Chem Soc 127, 10693-10698. http://dx.doi.org/10.1021/ja051947+

Verma A, Simrad JM, Rotello VM. 2004.Tunable reactivation of nanoparticle-inhibited $\beta$-Galactosidase by Glutathione at intracellular concentrations. Langmuir 20, 4178-4181. http://dx.doi.org/10.1021/la036183v

Tanaka T, Sawano M, Ogasahara K, Sakaguchi Y, Bagautdinov B, Katoh E, Kuroishi CA. Shinkai A, Yokoyama S, Yutani K. 2006. Hyper-thermostability of CutA1 protein with a denaturation temperature of nearly $150^{\circ} \mathrm{C}$, FEBS Letters 580, 4224-4230. http://dx.doi.org/10.1016/j.febslet.2006.06.084

Harada A, Yoshioka Y, Kawamura A, Kojima C, Kono K. 2007. Effect of Polycarboxylate blocks on the Amidase activity of Trypsin through complexation with PEG/Polycarboxylate block monomers, Macromol Biosci 7, 339-343. http://dx.doi.org/10.1002/mabi.200600199

Wenck K, Koch S, Renner C, Sun W, Schrader TJ. 2007. A non-covalent switch for Lysozyme, J Am Chem Soc 129, 16015-16019. http://dx.doi.org/10.1021/ja075507p

Schumann J, Bohm G, Schumacher G, Rudolph R, Jaenicke R. 1993. Stabilization of Creatinase from Pseudomonas putida by Random Mutagenesis. Protein Sci 10, 1612-1620. http://dx.doi.org/10.1002/pro.5560021007

Ganguli S, Yoshimoto K, Tomita S, Sakuma H, Matsuoka T, Shiraki K, Nagasaki Y. 2009. Regulation of Lysozyme activity based on Thermotorelant protein/Smart Polymer Complex Formation. J Am Chem Soc 131, 6549-6553. http://dx.doi.org/10.1021/ja900786z

Ganguli S, Yoshimoto K, Tomita S, Sakuma H, Matsuoka T, Shiraki K, Nagasaki Y. 2010. Improving the heat resistance of Ribonuclease $\mathrm{A}$ by the addition of Poly( $N, N$-diethylaminoethyl methacrylate)-graft-poly(ethylene glycol) (PEAMA-gPEG), Macromol Biosci 10, 853 - 859. http://dx.doi.org/10.1002/mabi.200900432

Borkakoti N. 1983. The active site of ribonuclease A from the crystallographic studies of ribonuclease A -inhibitor complexes Eur J Biochem 132, 89-94. http://dx.doi.org/10.1111/i.1432-1033.1983.tb07329.x

Sreerama N, Woddy RW. 2000. Estimation of Protein Secondary Structure from Circular Dichroism Spectra, comparison of CONTIN, SELCON, ad CDSSTR Methods with an Expanded Reference Set, Analytical Biochemistry 287, 252260. http://dx.doi.org/10.1006/abio.2000.4880

Kurinomaru T, Tomita S, Kudo S, Ganguli S, Nagasaki Y, Shiraki K. 2012. Improved complementary polymer pair system: switching for Enzyme activity by PEGylated Polymers. Langmuir 28, 4334-4338. http://dx.doi.org/10.1021//a2043312

Harada A, Kataoka K. 2003. Switching by pulse electric field of the elevated enzymatic reaction in the core of poly-ion complex micelles. J Am Chem Soc 125, 15306-15307. http://dx.doi.org/10.1021/ja038572h

Bronich KT, Kabanov AV, Kabanov VA, Yu K, Eisenberg A. 1997. Soluble stoichiometric complexes from poly(n-ethyl-4vinylpyridinium) cations and poly(ethylene oxide)-block-polymethacrylate anions. macromolecules 30, 3519-3525.

Katayose S, Kataoka K. 1997. Water-soluble poly-ion complex associates of DNA and poly(ethylene glycol)-poly(Llysine) block copolymer. Bioconju Chem 8, 702-707. http://dx.doi.org/10.1021/bc9701306 